\title{
PROLEGÓMENOS SOBRE PUBLICACIONES ELECTRÓNICAS DE POESÍA EN LENGUA ESPAÑOLA
}

\author{
Reyes Vlla-Belda*
}

Resumen: Este trabajo pretende informar sobre algunas de las publicaciones electrónicas de poesía en español así como resaltar ciertas innovaciones o cambios que estos nuevos soportes aportan al proceso de comunicación poética. No se trata de un estudio exhaustivo ni siquiera representativo de las fuentes existentes ya que sólo escogemos aquéllas que sirven a nuestros objetivos. Por tanto se trata de una selección intencional o purposive sample ya que sirve para ilustrar nuestras observaciones.

Palabras clave: publicaciones electrónicas, revistas de poesía.

\begin{abstract}
This paper reviews selected electronic publications devoted to Spanish poetry. It also seeks to identify changes and innovations which new media are introducing into the poetic communication process. This is not an exhaustive study, nor does it pretend to be representative of the many diferent resources available. We have only selected those resources which are relevant to our focus a purposive sample, in other words.
\end{abstract}

Key words: electronic publishing, poetry journals.

\section{Introducción}

La conversión de las revistas y publicaciones científicas al medio electrónico surgió como solución práctica a los problemas de edición debido a la creciente oferta de material publicable: retrasos en la producción, aumento de costos, conservación del medio ambiente así como para facilitar una mayor accesibilidad del documento al posible lector que, de esta forma, podría obtenerlo más fácilmente desde su lugar de trabajo o su casa. Inicialmente, no se trataba más que de poner el mismo vino en odres nuevos, como dirían los castizos, es decir usar el ordenador como un mero vehículo. En este sentido, A. Walton Litz (1) comenta con cierta gracia que para los humanistas de los setenta y los ochenta el ordenador desempeñaba más o menos la misma función que una fotocopiadora: como ella, era un instrumento eficaz sometido al servicio de unos métodos tradicionales. Para William McCarty (2), estudioso de la edición electrónica de la información científica, la asimilación del ordenador está siguiendo las mismas etapas que las demás nuevas tecnologías:

first, in the imitative phase, it tends to be used as if it were merely an improvement upon and replacement for what is already known; then, after some time, we begin to see it as genuinely new, and to realize that its newness alters how we think about the world.

Como aventuraba McCarty, lo que parecía una simple conversión del soporte de papel al electrónico ha creado implicaciones más profundas y plantea un sinfín de cues-

* Indiana University. USA. Correo electrónico: rvilabel@indiana.edu.

Recibido: 18-5-98. 2." versión: 15-2-99. 
tiones todavía sin resolver. De hecho, como apunta John Unsworth (3), la electronificación de la comunicación científica está imponiendo cambios con repercusiones: «éticas, filosóficas, económicas, formales, genéricas, legales y, en muchas ocasiones, prácticas así como de formas de proceder». Walton Litz (4) considera que, en los últimos diez años, humanistas y científicos han descubierto el impacto de los recursos electrónicos y los cambios que están introduciendo: desde afectar a la función del editor a cambios en el concepto de autoría, lectura, lectores y hasta en la misma naturaleza del propio texto. Este último es uno de los cambios más notorios. Hace apenas unos años, una publicación electrónica era sólo la versión automatizada de una publicación impresa. Conservaba un formato semejante y una estructura lineal, propia del papel y la impresión, imponiendo en el lector un tipo concreto de lectura de aquel tipo de soporte o medio y sin adaptarla al nuevo. La única diferencia fundamental, o para muchos el único inconveniente, es que había que leerlo en la pantalla del ordenador o imprimirlo para disponer de una copia en papel. Pero en los últimos años han surgido nuevas formas de publicación electrónica que se van separando y diferenciando de aquéllas con soporte de papel y que presentan nuevas características. Kling y McKim (5) señalan la hetereogeneidad de los nuevos documentos electrónicos o e-media forms tales como: las listas de distribución, los LISTSERV, las creaciones de páginas personales en la red (la mayoría autopublicadas) o los grupos de discusión. Constantemente surgen nuevos tipos de documentos.

Esta nueva explosión de soportes documentales nos obliga a definir el concepto de «publicación» electrónica. En general, las múltiples definiciones que podríamos recoger sobre este concepto insisten en el proceso de distribuir o hacer accesible información escrita. Ted Nelson (6), padre del hipertexto, pone el énfasis en la raíz del término al afirmar que: «"publishing" suggests use by the public» (1/9). La poesía moderna, especialmente la publicada electrónicamente, enlaza perfectamente con este concepto ya que aspira a mantener un contacto vivo con sus lectores facilitando su intervención y participación activa en el propio proceso creativo. En este sentido, Janet Murray (7) adelanta que surgirá una nueva forma de lectura de los documentos cibernéticos ya que el autor, aunque en control de la obra, permitirá una mayor libertad al lector que busca integrarse en el proceso creativo. Existen ya publicaciones de poesía en disquetes que facilitan una lectura individualizada mediante la ayuda del hipertexto que deja que el lector abra y haga connexiones o links a su elección.

La poetisa cubana exiliada Carlota Caulfield ha publicado Visual Games for Words \& Sounds/Juegos visuales para sonidos y palabras, un libro de poesía electrónica o «hiperpoemas» para ser leído en un Mackintosh. Según ella, los poemas o «hiperpoemas» tienen movimiento, sonido y la posibilidad de ser leídos en forma no lineal y requieren el juego interactivo del lector (información procedente de Tiempo Latino, 10 agosto, 1994).

De ahí que, a la hora de escoger un área dentro del campo de las Humanidades, optemos por la poesía ya que creemos que es un género literario que se va a beneficiar del nuevo medio. Dentro del panorama creciente de las fuentes de información electrónica en español, nos proponemos seleccionar aquellas fuentes que publican poesía original. 


\section{Material y métodos}

\section{Material}

\section{Selección de las fuentes}

La tarea de búsqueda y selección de las fuentes documentales para el presente estudio no ha sido fácil. La búsqueda directa en la World Wide Web resultó tediosa y sin resultados positivos ya que los directorios electrónicos y search engines tales como Yahoo o Alta Vista ofrecen miles de respuestas que, por su número, resultan imposibles de comprobar. Más beneficiosa fue la consulta directa a directorios, especialmente la versión online del editado por la Association of Research Libraries Directory of Electronic Journals and Newsletters, consultas planteadas a listas de usuarios y sobre todo la consulta directa a especialistas.

\section{Resultados y discusión}

\section{Publicaciones electrónicas}

Podemos hablar de diversos tipos de soportes documentales a los que, por su relación con el lector, clasificamos como géneros.

I Las páginas personales Web: Es un género que está creciendo muchísimo pues cada día se publican páginas nuevas. El concepto de página personal es en sí todavía confuso. Lo que inicialmente fue una tarjeta de visita electrónica o un perfil de la personalidad del autor/a se ha convertido en algo así como un retrato de su mente. Marcia J. Bates y Shaojun Lu (8), en un estudio reciente, señalan que todavía se encuentran en incipiente estado de desarrollo y que la variedad y libertad en temas y estructura son el único denominador común. Así, a veces el autor de la página intenta crear su propio perfil personal $y$, entre otras cosas, dar a conocer sus gustos, aficiones o lecturas creando una especie de cajón de sastre en el que aparecen entremezcladas informaciones de todo tipo, desde datos biográficos hasta fantasías. Resulta habitual encontrar selecciones poéticas en páginas de este tipo. En algunos de estos casos, y si el autor de la página ha escrito versos, es frecuente que los publique. Un ejemplo de este género es: Café Gabriel (http://www.wp.com/cafe-gabriel/poesi/homec.hmtl) que incluye, junto a un poema titulado «A los letrados» y firmado por Gabriel Martínez Aguirre, otros de Borges o Paz. En algunos casos, resulta muy difícil identificar lo que es original de lo que es selección de otros. Los poemas de poetas reconocidos aparecen, por lo general, identificados pero sin referencias bibliográficas. De los poemas originales no se facilita información alguna: fecha de creación, si han sido publicados o son inéditos, etc. La única opción es contactar electrónicamente con su autor.

Otro tipo de página personal es la colectiva. Muchas de ellas, simplemente recogen selecciones de poetas famosos. Un ejemplo es la excelente Dictionary of Mexican Writers (http://www.columbia.edu/gmo9/poetry/index.html) pero que no podemos incluir en este estudio al no ser material original. Sin embargo, en esta misma línea, hay otras páginas colectivas que también cumplen una función antológica pero que recogen poemas inéditos. Un buen ejemplo de este tipo de publicación es Escritores de 
Magallanes (http://www.fcmr.com/austro/poesóa/home.htm). En esta página, unos poetas de la Patagonia chilena dan a conocer parte de su obra, junto con una brevísima presentación biográfica, a la vez que permiten un contacto individual y directo a través de su correo electrónico.

II Las listas de usuarios: Es otro nuevo género de comunicación electrónica. Surgió de la posibilidad de contacto directo y casi simultáneo entre personas interesadas por un mismo tema. Un ejemplo es el Listserv Chile-Humanidades, también conocida como Chile-H, y que cuenta con una página electrónica en la que informa sobre su propósito, participantes, publicaciones etc.,... (http://hermes.es.uh.edu/fchris/chileh.html). Se define como un foro privado no moderado sobre las Humanidades y las Ciencias Sociales en el Chile de hoy. Organiza un concurso anual de poesía inédita en español. Paralelamente al concurso se origina un debate en el que se discuten temas relacionados con la creación poética. El medio posibilita una discusión en la que intervienen participantes repartidos por todo el planeta.

III Las revistas literarias: Es otro género que, aunque procedente de su homónimo con soporte en papel, se encuentra en proceso de cambio. Las revistas electrónicas ofrecen la posibilidad de contabilizar a los lectores potenciales; incluyen la dirección electrónica de muchos de los poetas, lo que estimula una comunicación directa entre autor y lector, ofrecen la posibilidad de adquirir otros documentos y hasta incorporan sonido.

El contador de visitantes de página es una forma de registrar el número de los que "visitan» una página electrónica. De este modo, sus creadores pueden medir su difusión. Es cierto que no todos los que visitan una revista electrónica la leen y sin embargo quedará registrada. De forma semejante, es difícl saber si todos los compradores de una revista de poesía la leen o si la comparten con otros lectores. A pesar de estas limitaciones, el número de compradores de una publicación es la mejor forma de conocer su difusión. Del mismo modo, el contador de visitantes de una página electrónica facilita información sobre su posible difusión y, por tanto, sobre su éxito o aceptación entre los lectores.

Como mencionamos antes, no existen muchas revistas electrónicas en español dedicadas a la literatura y menos aún a poesía inédiia. Las cinco revistas que describimos a continuación, escogidas entre un total de una docena, cumplen con todos estos requisitos. El otro factor decisivo para incluirlas en nuestro estudio fue el geográfico. Cada una de las publicaciones electrónicas seleccionadas procede de un país de habla hispana: Argentina, Chile, España, Méjico y Venezuela. Este criterio amplía las perspectivas - de un sólo país a varios del mundo hispano- a la hora de observar el impacto que puedan tener las revistas electrónicas. Por último, nuestro propósito no es realizar un estudio general y exhaustivo sino ilustrar el proceso de cambio que están sufriendo estos nuevos medios de comunicación.

\section{El Telar de Ulises}

Localizador: (http:www.cpd.us.es/wwwuser/bibemp/ulises.htm).

Tipo de documento: revista electrónica de creación literaria. Creada por la biblioteca de la Escuela Universitaria de Estudios Empresariales de la Universidad de Sevilla en colaboración con el suplemento cultural «La Mirada» del periódico «El Correo de Andalucía». Números: volumen 1, número 1, 1996. No se especifica pero podría ser anual. 
Caraterísticas de la página Web: Contiene ilustraciones en color. (Facilita los nombres de los ilustradores en la sección índice). Un bloque de texto justifica el título: el mito de Ulises y la espera de Penélope tejiendo en el telar.

Incluye un índice (pinchable) que da opción al lector a escoger entre los tres grandes bloques de la revista:

- Prolegómenos.

- Indice de la revista.

- Poesía en el Internet.

Por último, dispone de contador de visitantes pero no da opción a que los usuarios hagan comentarios sobre la página y sólo facilita una dirección electrónica a la que no se puede acceder pinchando directamente.

Toda la estructura de la página sigue un formato muy rígido como consecuencia de aplicar una concepción más bien inspirada en el papel que en la pantalla del ordenador. No se beneficia lo suficiente de las posibilidades del medio electrónico. Como ejemplo, el lector debe volver constantemente a los índices iniciales para seguir leyendo las diferentes secciones en lugar de contar con puntos automáticos de búsqueda y selección en cada página.

Contenido: En los Prolegómenos, se afirma que la revista está abierta a todos los miembros de la comunidad universitaria de Sevilla y a los que deseen colaborar, exigiendo a cambio calidad y profesionalidad. Además, justifica la relación poesía-tecnología y reconoce las ventajas de la red Internet. Gracias a ella, afirman «la poesía puede llegar más lejos que un pequeño libro editado en una remota provincia, o una revista con escasos medios económicos. El reto es grande. Desde cualquier punto del mundo se podrá acceder a esta revista de poesía».

El Índice facilita la lista de colaboradores e ilustradores.

En la página de presentación, los editores piden disculpas por los errores debidos a torpezas propias del medio. Se proponen dar una visión de la poesía andaluza y española en general, dando a conocer poemas inéditos o publicados en revistas. El primer número incluye dos o tres poemas de ocho poetas diferentes, junto con breve información personal. Cuenta también con secciones de Recensiones y Críticas y de Ensayos y Traducciones.

Por último, Poesía en el Internet es una sección dedicada a Webs de Literatura Electrónica en el Internet en la que se facilitan doce direcciones informáticas relacionadas con este tema.

\section{Evaluación de la publicación}

Tenía que ser en Sevilla, en el corazón de Andalucía, tierra de poetas y amantes de la poesía, donde surgiera una iniciativa como ésta. Lo que no deja de sorprender es que se cree bajo los auspicios de la biblioteca de la Escuela de Estudios Empresariales. La revista tiene un planteamiento serio y riguroso y busca la calidad en sus contenidos. Sus editores son conscientes de que a través del medio electrónico alcanzarán una mayor difusión. 


\section{Péndulo}

Localizador: http;//www.hypergraphia.com/pendulo/.

Tipo de documento: revista literaria, editada por Hypergrahia, empresa del grupo editorial Iberamericano. Número: Sin identificar aunque por lo que se deduce de los archivos, en total -impresos y electrónicos - se han publicado quince números.

Caraterísticas de la página Web: En la parte superior, un pequeño bloque de texto explica que la revista se inició en 1992 en papel y que, desde marzo de 1995, es la primera revista mexicana en la red. Sin embargo, la publicación parece estar difunta, de la que sólo queda el esqueleto dentro de lo que los editores llaman «el cementerio de la red mundial de computadoras» aunque sus restos presentan lo que quienes la iniciaron llaman «los restos de una fantasía literaria». Por esto precisamente resulta difícil su catalagoción ya que, sin dejar de ser un documento electrónico de creación literaria, incluyendo poesía, ahora sólo cuenta con el archivo y no parece haber publicado nada nuevo desde 1996.

En letras visibles y móviles que se pueden pinchar anuncia estar hecha por $\mathrm{Hy}-$ permedia. Al seleccionar esta opción, se facilita información de la empresa diseñadora. A ambos lados del nombre aparece información sobre el «concurso de páginas www méxico», de la que Péndulo fue finalista y, a la derecha, un anuncio sobre un libro «Mercadotecnia e Imagen en Internet» del que son autores los creadores de la página.

El índice de las secciones está hecho a base de imágenes móviles - algunas difíciles de interpretar - y otro de texto: Poesía, Narrativa, Teatro, Entrevista, Ensayo Celulósica, La Plástica, Ensueños, Editorial, Correo. Al seleccionar algunas de estas secciones, como por ejemplo Narrativa o Entrevista, están vacías. Continúa empleando iconos y gráficos móviles en páginas sucesivas, sirviéndose de ellos como puntos de búsqueda de información o links. Muchos textos van acompañados de ilustraciones. Facilita los nombres de ilustradores y fotógrafos.

Al seleccionar la categoría de poesía, se ofrecen dos posibilidades de las que no se explica nada, pero que parecen ser los títulos de dos obras - no se especifica si son inéditas - pertenecientes a dos poetas diferentes. Ambas permiten establecer comunicación electrónica con los poetas. A continuación se plantean dos opciones: 1) leer un texto introductorio sobre los poemas, una especie de ensayo sobre el contenido y el estilo del autor escogido y 2) acceder a los poemas.

\section{Evaluación de la publicación}

Resulta muy difícil de evaluar ya que como publicación electrónica parece estar difunta pero sin embargo sigue siendo un archivo y fuente electrónica documental de un proyecto literario que contaba con ciertas aportaciones interesantes. Al parecer, se trataba de una revista literaria y experimental de valor. Su presencia, además, plantea un nuevo problema. Cuando las publicaciones periódicas impresas dejan de publicarse ya no se pueden recibir o comprar; sus colecciones quedan relegadas a estantes en donde acumula polvo y, con frecuencia, terminan por relegarse a un archivo donde, salvo en raras ocasiones, no son consultadas. Por el contrario, las revistas electrónicas que dejan de publicarse siguen apareciendo entremezcladas con las que aparecen periódicamente, lo que dificulta posibles búsquedas y selecciones documentales. Este es un problema que habrá que plantearse en un futuro. 


\section{Internauta Poesía}

Localizador: http://www.poesia.com/index 2.html.

Tipo de documento: revista de poesía argentina y latinoamericana. Contiene poemas inéditos, anticipos de textos de próxima publicación, reproducción de libros que ya no circulan o de difícil acceso y material de archivo. Dirigida y creada por Martín Gambarotta y Emiliano Pérez Pena. Cuenta con un consejo de redacción, galería de arte, diseñadores y nombres de colaboradores en cada número. La publicación ofrece además servicios de librería facilitados por amazon.com. Número: número 3, junio 1997. Publicación trimestral.

Caraterísticas de la página Web: Cuenta con una cabecera móvil de diseño gráfico. Arriba de la cabecera móvil, ofrece información sobre: servicios, librería, cool sites, staff o e-mail. Es la única revista de las seleccionadas que ofrece conexión a motores de búsqueda como Excite o Java. Contiene información bilingüe (español-inglés) sobre el propósito de la publicación. Incluye un índice de las distintas secciones con las colaboraciones de ese número. Las secciones son: Inéditos; Poesía inédita; Poesía argentina de los 80; Galería de arte; Rescate (de obras); Notas; Archivo.

Incluye información sobre otros servicios de interés: concursos internacionales de poesía; servicio de búsqueda de material bibliográfico on-line... También dispone de un contador de visitantes.

En cuanto a la presentación y el formato, se aleja mucho más del resto de las demás revistas electrónicas analizadas que se basan en una concepción tradicional basada en el soporte de papel: cuenta con muchos gráficos móviles, capacidad de establecer conexiones diversas, vueltas de página sin necesidad de volver al índice inicial constantemente... La mayor ruptura con el formato tradicional es la posibilidad de conectar y hacer una búsqueda bibliográfica e incluso de comprar un libro electrónicamente vía amazon.com.

Contenido: En la sección de Inéditos facilita una brevísima información sobre el poeta y su obra junto a la selección de los poemas escogidos.

\section{Evaluación de la publicación}

En cuanto al contenido, parece una revista rigurosa y que tiene unos criterios de selección literarios. No especifica cómo selecciona sus materiales pero ofrece una dirección electrónica para comunicarse con ellos.

\section{Letralia. Tierra de Letras}

Localizador: http:// www.nexus.net.mx/letralia/htm y en versión ASCII.

Tipo de documento: primera revista literaria publicada desde Venezuela, país de gran legado literario pero con pocas oportunidades para que los escritores jóvenes publiquen su obra. Son conscientes de las posibilidades que ofrece el soporte electrónico como alternativa más factible que el medio de soporte en papel para que los autores que nunca han publicado puedan hacerlo. Abierta a otros países del ámbito hispanoamericano. Incluye escritos inéditos. Dirigida y creada por Jorge Gómez que es el di- 
rector y un equipo de poetas, escritores y artistas de Venezuela, Argentina y Puerto Rico. La revista da prioridad al contenido sobre la forma ya que, consciente de que muchos poetas o amantes de la poesía no están necesariamente conectados a la red, cuenta con miembros en su Consejo Editorial que tampoco lo están pero a los que se les informa sobre los contenidos de la revista y se les pide su participación. Fecha de publicación: edición 31, publicada el 1 de Septiembre de 1997. Se publica regularmente desde mayo de 1996, el primer y el tercer lunes de cada mes.

Contenido: Editorial; Noticias culturales; Entre bases: Información sobre concursos literarios; Literatura en Internet; Artículos y reportajes; Sala de Ensayo; Las letras de la Tierra de las Letras: Segmento creativo; El buzón de la Tierra de las Letras: Cartas de los lectores; Post scriptum: cita textual extraída de la obra de un gran escritor.

En general establece conexiones con páginas personales de creación.

\section{Pares cum Paribus}

Localizador:(http://www.Uchile.cl/facultades/csociales/pares/pares2/ portada2.htm). Tipo de documento: Revista de Literatura y Arte. Oscar Aguilera y Margarita Schultz son los editores. Creada por la Universidad de Chile, Facultad de Filosofía y Humanidades, Departamento de Literatura, aunque en el número dos ha pasado a depender de la Facultad de Ciencias Sociales. Número: número 2, abril 1996. (Aunque se ha publicado en 1997). No se indica periodicidad.

Caraterísticas de la página Web: Incluye título de la publicación, el organismo que la publica, así como número y año. Facilita el nombre del editor y la editora de arte asf como sus direcciones electrónicas, aunque no invita a comentarios o evaluaciones. No incluye gráficos de ningún tipo. Al final de la página figura una flecha por la que, pinchando en ella, figura un índice de las secciones: poesía, narrativa, narradores jovenes, ensayos y arte con los nombres de los colaboradores en esta edición.

A pesar de que cuenta con sonido, rasgo éste muy interesante pues permite escuchar el recitado en voz del poeta, dispone de poca sofisticación gráfica y por su concepción se asemeja más a una revista tradicional en soporte de papel.

Contenido: Los editores en su nota afirman que quieren crear un espacio común para los ẹstudiosos de las humanidades y los credores literarios. Contiene poeśa inédita de calidad.

\section{Evaluación de la publicación}

Aunque con pocas novedades tecnológicas, la calidad de las contribuciones parece ser de alto nivel. Parecen haber pasado por un período de crisis: cambios en la edición, retrasos, etc. pero parecen determinados a seguir adelante con este proyecto.

\section{Conclusiones}

Obviamente, el estudio de cinco casos no permite establecer conclusiones generales pero sirve para ilustrar algunas de las soluciones que la Web ofrece a poetas y lectores. Además, estos casos ponen de relieve problemas y ventajas a los que se enfrentan las publicaciones electrónicas, consecuencias ambas del proceso de transformación que se está operando al pasar de un soporte al otro. 
La estructura de algunas de las revistas electrónicas analizadas es imitativa: es decir, imita la de las revistas en papel, que a su vez adoptaron la del libro. Un ejemplo es El Telar de Ulises. Los diseñadores de la página no se plantearon un diseño nuevo beneficiándose de las ventajas que ofrece el medio electrónico, sino que se limitaron a seguir el carácter lineal propio de una publicación impresa. Esto se deduce al tener que ir de una pantalla a la otra teniendo que volver siempre a un índice textual. Sin embargo, no todas las revistas electrónicas analizadas siguen este modelo. Otras, como Internauta Poesía, están cambiando su estructura adoptando, como definió Marshall McLuhan, una de tipo mosaico, característica de los medios de comunicación del siglo XX. El ordenador facilita el acceso a información diferente y múltiple desde cada pantalla.

En ninguno de los medios analizados hemos encontrado un uso pleno de la capacidad de incorporar ventanas con información diferente y simultánea en una misma pantalla, beneficiándose de lo que Murray (9) ha llamado «the kaleidoscopic power of the computer». Existen ya poemas publicados con hipertexto, como los hiperpoemas de la poetisa hispana Carlota Caulfield, a los que aludimos antes, que permiten ir seleccionando y explorando el poema a medida que se va leyendo, escogiendo entre las distintas opciones que ella ofrece. Este mismo recurso ha sido utilizado en una página Web de una conferencia argentina de hiperpoemas pero no lo hemos encontrado en ninguno de los casos analizados en nuestro estudio. Sólo queremos apuntar que herramientas como éstas alterarán la naturaleza del proceso comunicativo ya que permiten que el lector tome una parte cada vez más activa en el proceso creativo.

Otra de las innovaciones que está alterando la estructura de este nuevo medio es la posibilidad de comunicación. A través del papel, la comunicación tiene un carácter cerrado y estático, es decir, el medio no facilita una comunicación entre autores, editores y lectores. Si el lector desea comunicarse con ellos puede hacerlo, pero no de forma espontánea, ya que tiene que escribir y enviar esa información a la empresa editorial, proceso que muchas veces no se inicia por el tiempo que lleva. Además, las restringidas ediciones impresas marcaban un distanciamiento entre el poeta y el lector que ahora puede llegar a romperse. Casi todos los nuevos documentos electrónicos analizados en este trabajo ofrecen al lector la posibilidad de comunicarse - vía correo electrónico- con el poeta. El lector puede hacer una consulta, aclarar un concepto o simplemente, dar a conocer su reacción personal al poeta haciendo posible y real la «teoría de la respuesta de los lectores» defendida, entre otros, por Stanley Fish o Norman Holland. Todas las revistas analizadas incluyen la posibilidad de comunicarse electrónicamente con los autores y/o la revista y para ello facilitan su dirección electrónica.

En algunos casos, las posibilidades de comunicación son mayores. Internauta Poesía, por ejemplo, ofrece el contacto directo con otros servicios de posible interés para el lector, como es el acceso a una base de datos, la búsqueda en un motor de búsqueda o el acceso a una empresa vendedora de libros.

Una característica común a todas las publicaciones analizadas en este estudio es la capacidad de incluir y jugar con tipografía, fotografía e ilustraciones. Capacidad que es un beneficio del nuevo medio electrónico y que supone una ruptura con las limitaciones del medio impreso. Desde las bellísimas ilustraciones del Telar de Ulises, pasando por los iconos de Péndulo, y terminando con los juegos de imágenes móviles de Internauta Poesía. Y lo mismo se puede decir de los juegos tipográficos de todas ellas. Como afirma Sven Birkets (11), la tecnología ha tenido un impacto en la presentación 
del propio texto impreso: «The stationary arrangements of language on a page is outmoded. The word, they say, has broken from that corral, is already galloping in its new element, jumping with the speed of electricity from screen to screen.»

Otro aspecto muy importante es que, en regiones como España o Latinoamérica con tanta escasez de papel y por consiguiente tan caro, las publicaciones electrónicas son la solución a los problemas editoriales. Revistas como Letralia y Pares cum Paribus aluden en sus comentarios editoriales a estos problemas. Los autores jóvenes, con obra escrita pero sin imprimir, ven en ellas la posibilidad de dar a conocer al público sus poemas. No es por eso sorprendente que este tipo de documentos, y especialmente las revistas electrónicas, hayan surgido en aquellas regiones donde existe una larga tradición poética: Argentina, Chile, Venezuela, México y España. Los editores de las revistas electrónicas, como es el caso de Letralia, son los primeros en reconocer las ventajas que ofrece este medio para los jóvenes que, de otra manera, no habrían contado con la posibilidad de dar a conocer sus creaciones a un público.

Las publicaciones tradicionales de poesía suelen tener por lo general una difusión geográfica muy restringida. Ahora, como menciona el editor de El Telar de Ulises, el medio telemático ofrece la ventaja de que las obras de creación puedan ser leídas por personas de cualquier parte del mundo.

Aunque la mayoría de las publicaciones mencionadas en este estudio no cuentan con muchos números, es posible anticipar algunos de los problemas que indudablemente se van a plantear en un futuro. Uno de ellos es la periodicidad aunque ésta varía de un género a otro. Así, ¿cada cuánto tiempo debe actualizarse una página personal? ¿Qué ocurre si alguien desea consultar un poema que se había incluido en una versión más antigua de la página y que ahora ya no se encuentra en la misma? $\mathrm{O}$ ¿qué ocurre cuando se desea consultar un número previo de la revista electrónica? Es cierto que muchas fuentes electrónicas incluyen la posibilidad de consultar el archivo, pero ¿qué ocurrirá con esos archivos dentro de $\mathrm{X}$ años, seguirán siendo disponibles? Especialmente relevante es el caso de la revista Péndulo que, al parecer, ha dejado de publicarse pero sus archivos permanecen a disposición de consulta de todos los interesados. ¿Hasta cuándo permanecerán en la red? ¿Quién decidirá sobre el cómo y el cuándo deberan ser eliminados?

Otro de los problemas del que sólo queremos dejar constancia es la edición. Muchas de las publicaciones nacen al amparo de instituciones educativas. Así, el Telar de Ulises surgí al amparo de la biblioteca de la Escuela de Empresariales. Por su parte, Pares cum Paribus, nació bajo los auspicios de la Facultad de Filosofía y Humanidades pero ahora depende de la de Ciencias Sociales. Péndulo, en cambio, creada por una empresa comercial, ha dejado de publicarse.

Como conclusión, vemos que las revistas electrónicas están pasando de una primera etapa inicial imitativa, en la que sólo se produjo un cambio de soporte - del papel al electrónico- a una segunda etapa de incorporación, asimilación y adaptación de las características del nuevo medio y sus efectos en las publicaciones. Como señalaba McCarty, éste es el proceso habitual en la incorporación de nuevas tecnologías. Poco a poco las características del nuevo soporte electrónico están afectando a las revistas de poesía, configurando un nuevo medio, que terminará por transformar el propio proceso comunicativo, especialmente la comunicación y particiación del lector. 


\section{Bibliografía}

1. LITZ, W. A. Afterword. En: The Literary Text in the Digital Age. 1996. Michigan UP.

2. McCARTY, W. A Potency of Life: Scholarship in an Electronic Age. Serials Librarian 23, núms. 3-4 (1993): p. 80-81.

3. UNSWORTH, J. Electronic Scholarship; or Scholarly Publishing and the Public. En: The Literary Text in the Digital Age. 1996, Michigan UP.

4. LITZ, W. A. Ibid.

5. KLING, R. y McKIM, G. Electronic Media and Scientific Communication: Opportunities, Complexities and Limitations. Documento inédito encargado por la OCDE. 1997 Center for Social Informatics, School of Library and Information Science, Indiana University Bloomington, agosto.

6. NELSON, T. H. 1987. Literary Machines. Edition 87.1. Publicado por el autor.

7. MURRAY, J. Hamlet and the Holodeck. The Future of Narrative in Cyberspace 1997. NY: The Free Press.

8. BATES, M. y SAOJUN, Lu. An Exploratory Profile of Personal Home Pages: Contents, Design, Metaphors. Online \& CD Rom Review. Diciembre de 1997, 21, 6, 331-339.

9. MURRAY, J. Ibid.

10. DOSS, P. Traditional Theory and Innovative Practice: The Electronic Editor as Poststructuralist Reader. En: The Literary Text in the Digital Age 1996. Michigan UP.

11. BIRKETS, S. The Gutenberg Elegies. The Fate of Reading in an Electronic Age 1994. New York: Fawcett. 